\title{
DESCARTES ON THE INTELLECTUAL NATURE OF HUMAN SENSE PERCEPTION: FROM THE INNERMOST SELF TO THE MATERIAL WORLD
}

\author{
DESCARTES SOBRE LA NATURALEZA INTELECTUAL DE LA \\ PERCEPCIÓN SENSORIAL HUMANA: DESDE EL YO MÁS ÍNTIMO AL \\ MUNDO MATERIAL \\ Modesto Gómez-Alonso
}

Recibido: 31/05/2015

Aceptado: 13/07/2015

\begin{abstract}
In this essay, I argue that a proper understanding of the Cartesian proof of the external world sheds light on some vexatious questions concerning his theory of sense perception. Three main points emerge from the discussion: a picture of the mind, conceived as the power of understanding, as essentially related to the physical world; an extension of rationality such that it includes a set of necessities that neither can be deduced from the principles furnished by pure understanding alone nor are to be found among the particular items of sense experience; and a conception of human sense perception as a composite power that includes sensory awareness as well as understanding, and so that establishes a sharp distinction between human and animal sensory awareness. As far as agency is a constitutive ingredient of human sense perception, Descartes' doctrine is in line with some current versions of a virtue epistemology.
\end{abstract}

KEYWORDS: Extended rationality; external world; ideas materially false; sense perception; understanding.

\section{RESUMEN}

En este artículo, argumento que una comprensión adecuada de la prueba cartesiana del mundo externo arroja luz sobre varios problemas, aparentemente intratables, que permean su teoría de la percepción sensorial. Tres aspectos sobresalientes emergen de la argumentación: un modelo según el cual la mente, 
concebida como la capacidad de comprensión, se encuentra constitutivamente vinculada al mundo físico; una extensión de la racionalidad que incluye entre sus componentes un grupo de necesidades que ni pueden deducirse únicamente de los principios básicos del entendimiento puro ni se encuentran entre los objetos concretos de la experiencia sensorial; y una concepción de la experiencia sensorial humana de acuerdo a la cual ésta es un poder compuesto que incluye tanto consciencia fenoménica como ejercicio intelectual, de forma que se establece una distinción tajante entre la sensación animal y la humana. En la medida en que la agencia es un ingrediente constitutivo de la percepción sensorial humana, la doctrina propuesta por Descartes es análoga a algunas versiones actuales de epistemología de virtudes.

PALABRAS CLAVE: Comprensión intelectual; ideas materialmente falsas; mundo externo; percepción sensorial; racionalidad extendida.

\begin{abstract}
Analysis shows the true way by means of which the thing in question was discovered methodically and as it were a priori, so that if the reader is willing to follow it and give sufficient attention to all points, he will make the thing his own and understand it just as perfectly as if he had discovered it for himself. But this method contains nothing to compel belief in an argumentative or inattentive reader; for if he fails to attend even to the smallest point, be will not see the necessity of the conclusion.
\end{abstract}

AT VII 155-56 / CSM II 110

In this paper I argue that, given the strict conditions imposed by radical scepticism on the Meditations' proof of the external world, such a proof might only be successful if its starting point is epistemologically certain as well as unintelligible in terms of a narrow self. This means that the Cartesian proof has to be conceived as a transcendental argument whose crucial premise is that one is the subject of propositional thinking regarding particular objects, and which, through an examination of the conditions for the possibility of such a thinking, is able to yield the result that the existence of an intelligible external world is such a condition. In this sense, the success of the proof depends on whether Descartes is successful in supporting the claims that, insofar as in a restricted sense the self is nothing else that unconditional understanding, it is per se unable to explain our recognitional powers, and that those powers are operative despite the sceptical scenarios advanced in the First Meditation. This 
is why the proof depends both on the argument for mind-body distinctness, and on Descartes' detailed argument to disambiguate the notion of sensation.

I will focus on the latter aspect, and show that, contrary to standard interpretations, Descartes conceived of thought as propositional thinking and of the mind as an intellectual as well as volitional faculty deprived of any sort of imagery, and so that by 'sensory ideas' he understood, not phenomenal (and thus corporeal) presentations of objects, but propositional conceptions of states of affairs. This is why sensory ideas are suitable candidates for being the starting point of the proof.

In section 1, I will introduce the issue of the alleged Cartesian equivocation on the notion of thinking, and argue that a pluralistic approach to it is plagued by fundamental problems. In section 2, I discuss the standard interpretation of the proof of the external world, and argue both that it is logically vulnerable and that it is unable to make sense of the text. In section 3, I propose an analysis of sensory ideas that is grounded on Descartes' discussion on the material falsity of sensory ideas, and argue that it provides us with a certain datum about the epistemic value of the proof. In section 4 , I reconstruct the proof, and show that it is far from negligible. Besides, I show how it clarifies several important issues, from the character of human sensation to the doctrine of the automatism of animals. The overarching thesis is that the Cartesian doctrine of the intellectual nature of human sense perception and his proof of the external world are closely related.

\section{DESCARTES ON SENSATION: THE RECEIVED VIEW}

It is part of the common lore of contemporary philosophy that Descartes was the originator of what might be called the "phenomenal conception of mind", to wit, that he expanded the concept of mind to include, besides propositional attitudes and 'pure' acts of thinking, raw sensations, emotions and feelings: a private world of mental imagery that, under the technical rubric of 'ideas', was as epistemically unassailable as ontologically isolated from the objects that were their presumed causes. When this conception is combined with the Cartesian doctrine that the nature of the mental substance is thinking, the result is an extension of the meaning of the concept of thought, so that it covers a wide variety of mental events, from beliefs and decisions to sensations, and includes as a genus a subset of faculties that goes from intellectual understanding to imagination and sense perception. As a result, 
thinking became for Descartes synonymous with consciousness, immediate awareness, or experience, terms which are the forerunners of direct acquaintance.

Interpreters have not failed to notice that Descartes' use of the word 'thought' deviates from common usage, ${ }^{1}$ and that, throughout his writings, he seems guilty of equivocation on the notion of thinking, operating with two incompatible concepts: a restricted and propositional-orientated notion which he took from the Schools and which, according to Zeno Vendler, conforms with "the idea of thought that we have" (VendLer 1991, p. 251), and the aforementioned extended notion that covers the whole of our mental life. Maybe the equivocation could be extenuated as a product of creative struggle, but the facts remain that the extended concept of thought takes precedence over the inherited conception (it seems more genuinely Cartesian), that this piece of revisionary metaphysics is unmotivated and counter-intuitive, and that it naturally leads to the infamous doctrine of the automatism of animals, whose lacking of thought entails lacking of sensory awareness.

The nature of this entailment is, however, puzzling. In order to deny sensation to animals Descartes' argument would seem to require both the general premise that sensation is a mode of thinking and the factual premise that animals do not think, namely, that they are deprived of conceptual or propositional thinking ('thought' in the restricted sense of the word). Insofar as it is quite plausible, the latter premise is necessary to warrant the conclusion that they do not have sensation. But all the logical force of the entailment depends on the former premise, which provides the middle term of the syllogism. The problem with this argument is that the middle term is equivocal, that there are then four terms in the syllogism, and so that the conclusion

\footnotetext{
1 "However, French and Latin usage was never as wide as that found in Descartes; at no time was it natural to call a headache or a pang of hunger a cogitatio or pensée. In fact, Descartes was consciously extending the use of the words 'cogitare' and 'penser.' This is brought out by the misunderstandings of his contemporaries" (KENNY 1968, pp. 68-9).

As I shall later argue, the misunderstandings were real, but their cause was not a supposed extension of the meaning of thought, but a complex theory of human perception. Human perception includes a raw sensation and an intellectual grasping of a thought: insofar as these two aspects are always conjoined in human experience, it is natural to call 'sensation' to the compound. Disambiguation is the task of the philosopher, who is not replacing common parlance, but clarifying it.
} 
doesn't follow: to play its part in the argument, sensation should have to be a mode of a thicker thought ${ }^{2}$ than mere phenomenal awareness.

This leaves us with four interpretative options: (i) Descartes' doctrines are irreparably inconsistent, he is guilty of an elementary blunder in logic; (ii) a Kantian approach which states that, according to Descartes, sensation is never possible without concepts, and so that substitutes a dualism based on the intrinsically intellectual nature of sensation itself for a dualism based on 'pure' experience (this approach would provide the thicker thought that saves the argument for the automatism of animals from being a formal fallacy); (iii) a resolute reading ${ }^{4}$ that claims that sensation, taken by itself, is neither a mode of thinking nor a mental event, ${ }^{5}$ that makes a sharp distinction between human and animal sensory awareness, and that underlines that, instead of extending the concepts of mind and thought, Descartes restricted both of them; and (iv) a pluralistic view that points out that the common element of all mental operations, however diverse they may be, is immediate awareness, and so that

\footnotetext{
${ }^{2}$ I am borrowing this term from E. Sosa, who distinguishes between a thinner and a thicker notion of thought, capturing with such concepts the difference between imagery and propositional thinking. See SoSA (2007, pp. 10-11).

3 That is the view proposed by James Hill in Descartes and the Doubting Mind. He claims that, insofar as the modes of imagining and sensing are relational (they depend on the intellectual and on the corporeal substances they relate), they "involve the intellect as a necessary constituent" (HILL 2012, p. 106), and so that, since Descartes denies an incorporeal substance to animals, "they are also incapable of sensory perception, hunger and pain in so far as these involve awareness and feeling and are not just the blind workings of the animal spirits and the mechanism of the body" (Id., p. 112).

${ }^{4} \mathrm{I}$ am borrowing this term from a well-known approach to Wittgenstein's Tractatus, a reading that, taking Wittgenstein at his word, takes very seriously his closing comments on the nonsensical character of the doctrines promoted throughout the book. With regard to Descartes' philosophy, it is the view I favour. Its nub is never to forget that one of the firmest points in the interpretation of Descartes is his robust conceptual dualism, and so that readings that threaten to blur the distinction between mental and physical states, or between personal and sub-personal faculties, are prima facie objectionable.

${ }^{5}$ According to this account, sensations are modes of corporeal substances. Nevertheless, this does not mean that they are explainable in terms of extension (they are not). Our claim is dual: that sensations cannot be predicated of a thinking thing, and that they only can be predicated of particular bodies (animal and human bodies). In this sense, this reading is fully compatible with an attributive trialism (two ontological substances or referents, three irreducible categories) such as the one famously proposed by John Cottingham. See CoTTINGHAM (1991a, pp. 23648).
} 
refusing rationality to animals Descartes was not committed to refuse them phenomenal sensing. ${ }^{6}$

Oddly as it seems the latter account is not only the vision of mind shared by most contemporary philosophers, but the more likely view that a charitable interpreter would attribute to Descartes. On the one side, and due to the Cartesian remapping of categories, toothaches and pains have become paradigmatic examples of mental states, at the same time that an austere and down-to-earth conception of thought has prevented the outrageous consequences of the Cartesian doctrine. Headaches are mental stuff, but not thoughts. Animals can be nonconceptual without being nonsentient. We can have it both ways: an expanded conception of mind together with a restricted notion of thought. On the other side, the previous conception could be presented as an interpretation (and a partial justification) of Descartes' approach. It would be enough to make use of his definition of thought in terms of indubitable knowledge, that is, in terms of immediate awareness, and,

\footnotetext{
${ }^{6}$ Three out of the four options are revisionist in nature. The Kantian approach makes Descartes defend that sensation is a (partial) mode of conceptual thinking and that the nature of the mind is conceptual thinking (it is a view based on a restricted conception of the three elements involved: mind, thought and sensation). The resolute reading makes Descartes subscribe to the doctrines that sensation is a mode of corporeal substances and that the nature of the mind is conceptual thinking (it is an account grounded on a restricted view of only two of the elements involved: mind and thought). The pluralistic approach makes Descartes endorse that sensation is a mental event, but not a mode of thinking, and that the nature of the mind is consciousness (and so it combines an extended notion of the mind with a restricted notion of thought).

It seems obvious that, though able to rescue the Cartesian argument from logical inconsistency, the Kantian reading confronts us with a view at least as unpalatable as the original one, adding to the automatism of animals the gratuitous postulate of an asymmetrical relation of dependency between experience (seeing a green patch) and propositional experience (seeing that a green patch is in front of me), and so exposing Descartes to the charges of leaving no space to sub-personal powers and of making of sensation (a paradigm, if any, of an unreflective operation) the result of a reflective and highly sophisticated process. For making sense of Descartes what has to be revised is the account of his supposed doctrines, and not of his supposed argument against the common sense conception of animals. Both the resolute and the pluralistic approaches would acquit Descartes of the charge of being (borrowing from John Cottingham) "a brute to the brutes". See COTTINGHAM (1991c, pp. 163-72).

7 "Thought. I use this term to include everything that is within us in such a way that we are immediately aware of it. Thus all the operations of the will, the intellect, the imagination and the senses are thoughts" (AT VII 160 / CSM II 113).
} 
focusing on content rather than verbal expression, to consider his misleading terminology as a mere holdover of his Scholastic education, to release his ground-breaking conception of the mind from verbal disputes.

There are, however, at least two drawbacks of this approach. The first is that it leads to a division of the mind into two compartments, one containing phenomenal experiences and the other containing 'thoughts' in a quasi-Fregean sense of the word: constructions out of concepts that are the objects of a shared understanding (they are not private in the sense that sensations are private) and the subject-matter of a diverse range of propositional attitudes, such that they are the only candidates to become judgements, and so bearers of truth-values. That division of the mind becomes more accentuated after considering that, according to this view, awareness is the common aspect of the operations of diverse and mutually irreducible mental faculties, from rational powers to memory, imagination and sensory perception. This raises a battery of questions: Is this pluralistic conception of the mind not at odds with Descartes' conspicuous doctrine of the indivisibility and the simplicity of the soul, ${ }^{8}$ a doctrine which explicitly opposes to the Aristotelian theory of the mind as composed of subminds? Are not propositional attitudes personal operations done by the whole mind, and so incapable to be explained by subpersonal mechanisms? What is the role of awareness? Is not Descartes positing a useless monitoring device, useless since, instead of explaining and unifying mental operations, of providing for them the same ground of possibility, it is a concomitant aspect, a mere epiphenomenal appurtenance to those very operations? What these questions indicate is that Descartes' definition of the mind in terms of certainty needs to be deeply reconsidered, but not because epistemological certainty is not the mark that he uses to identify mental items (it is). Rather because the scope of certainty is for him much more limited than for empiricists such as Locke and Russell.'

All the references to the works of Descartes are to volume and page in AT. According to the standard procedure, I have also used the English translation of Descartes' philosophical writings by Cottingham, Stoothoff, Murdoch, and Kenny.

8 See, for example, AT VII 86 / CSM II 59.

${ }^{9}$ As far as I am aware the only Cartesian scholar to notice that the demon scenario cast doubts upon phenomenal sensation, namely, upon qualitative feelings such as seeing a green patch, feeling a pain, or craving for a soft drink, is John Cottingham. From this very fact Cottingham mounts a searing criticism on Descartes, who, inasmuch as "the most (...) the hyperbolical doubt could allow him to assert as essential to his nature is that —in the narrowest sense- he 
The second problem of this position is quite obvious. It is clear that Descartes didn't attribute thought to animals. But it is not less clear that he refused them a mind or a soul (AT IV 576 / CSMK III 304). This means either that his verbal inheritances are too philosophical operative for comfort or that for him 'mind' and 'rational mind' are interchangeable expressions.

\section{2. 'The PuZZLing nature of Descartes' proOF of the EXTERNAL WORLD}

In a celebrated passage from the Second Meditation, Descartes provides a list of activities that indubitably pertain to a thinking thing: a thinking thing is "(a) thing that doubts, understands, affirms, denies, is willing, is unwilling, and also imagines and has sensory perceptions" (AT VII 28 / CSM II 28).

John Cottingham (CotTingham 1991a, p. 238) has stressed the pause (captured by the Latin 'quoque' -'and also') that precedes the introduction of the capacities of imagination and sense perception, separating them from the first subset of the list, which contains 'pure' operations of the intellect and of the will. The oddity of presenting imagination and sense perception as activities of a thinking thing does not go unnoticed: Descartes, who later will call those faculties "special modes of thinking [my emphasis]" (AT VII 78 / CSM II 54), hastens to justify and clarify his claim, distinguishing between a 'restricted' and a lax meaning of 'sensory perception'. In a restricted sense, seeing a green patch or feeling an excruciating pain is nothing else than seeming to see a green patch or to feel a pain (AT VII 29 / CSM II 28), seemings whose certainty is independent of the existence of an external world and of their veracity, and so that qualify as modes of thinking. ${ }^{10}$ Only those seemings, detached of their

thinks" is not justified to "move from 'sum res cogitans' to 'sum res volens, sentiens, etc." (COTTINGHAM 1991b, p. 294).

This critique, although based on a correct insight, would undermine any possible proof of the external world, preventing it to get off the ground. It makes imperative to identify some element that, conjoining epistemic certainty and unintelligibility in terms of a narrow self, could count as sensory perception or as "the ideas of sensible objects" (AT VII 79 / CSM II 55).

${ }^{10}$ In order to avoid unnecessary complications in this context, I have focused on sensory perception. Descartes justifies the introduction of the imagination as a mode of thinking inasmuch as mathematical imagining is a way to convey and represent necessary relations, one that is dependent on the will and is guided by the understanding. Passive imagination, namely, the involuntary and derivative (from sensory awareness) imagery of reveries, daydreams, and dreams, does not qualify as a mode of thinking. This doesn't mean, however, that agency is 
causal underpinnings and of their epistemic status, are mental operations. In his usual way, Descartes manages to plant in his readers the seeds of a material whose philosophical development will have to wait until the Sixth Meditation, where sense perception will be instrumental to the proof of the external world.

The structure of this notorious proof is far from clear, but there seems to be something close to a consensus on some of its basic components.

Firstly, it seems uncontroversial that, discerning a restricted meaning of sensation, Descartes is pointing towards a private world of pains and colours, that is to say, towards a realm of sensory ideas (or qualia) that, even if they are causally and systematically related to a physical order, are logically independent both of the corporeal process of information's delivery and of the corporeal features presumably represented by their phenomenal contents. The mental order of sensory ideas is just independent of the physical order, whatever the latter may be. Accordingly, Descartes was an indirect realist, and thus he had to face the issues associated with such position, mainly the epistemological problem raised by the veil of ideas: how to come to terms with two irreducible and independent varieties of knowledge, the subjective and the objective. ${ }^{11}$

Second, and regarding the structure of the argument, it is assumed that the proof is composed of three steps. On the first step, Descartes appeals to the involuntariness of our sensations, a fact that, ruling out the possibility of being himself the cause of his sensory ideas, points to an external cause. On the

absent from human passive imagination: after all, and although reveries are not usually activated by the will, they are voluntary insofar as it makes sense to command a daydreaming person to focus. Imagining is attention-dependent, and attention (at least in many cases) is grounded on the will. For Descartes, even dreams are attended by reflection: the fact that sometimes, being aware that we are dreaming, it is up to us to interrupt (or not) the dream, seems to suggest interesting connections with the will, namely, with operations involving the whole person. On this issue, see, for instance, AT VII 358-9 / CSM II 248.

It goes without saying that due to the crucial nature of this topic for a correct understanding of the Cartesian proof of the external world this is an issue to which we shall return.

11 This reading seems neatly to fit with the first two grades of sensory perception such as they are presented in a celebrated passage from the Sixth Set of Replies. After all, the third degree of sensory response, inasmuch as it consists of judgements, "it is clear that it depends solely on the intellect" (AT VII 437 / CSM II 295), to wit, it is attributed to sensation only in virtue of a common mistake, as it were, as a sob to common parlance.

On the other hand, I am using 'objective knowledge' in a restricted sense of the expression, limited to knowledge of the physical world. The Meditator enters the realm of externality and objectivity after achieving knowledge of God and of true natures.

Análisis. Revista de Investigación filosófica, Vol. 2, n. ${ }^{\circ} 1$ (2015): 163-193 
second step, Descartes considers two scenarios: a Berkelian scenario where God (or another intellectual substance) ${ }^{12}$ is the cause of his sensations, and the commonsense belief that they "are produced by corporeal things" (AT VII 80 / CSM II 55). Insofar as the latter conviction is immediate, irresistible, and, unlike opinions that can be corrected by a proper use of reason, rationally incorrigible (one can discover that one's former opinion about the size of the sun was wrong, but what would count as discovering that one was in error when believing that there is a physical world? Does it make sense to talk of 'beliefs', and of 'errors' in this context?), it is one of the "teachings of nature", 13 and so it would be a categorial mistake to put it on a par with opinions and possibilities such as the first hypothesis. In other words, the scenarios are incommensurable, our 'belief' in the external world is not just a belief among others; with a higher epistemic standing than opinions (including apt or veridical opinions), convictions of this sort are so closely related to our rational framework that their falsity would result in the discredit of reason itself. ${ }^{14}$

12 The text mentions "some creature more noble than a body" (AT VII 79 / CSM II 55). It is seldom if ever asked why Descartes entertains these two related possibilities (and how they are related). Let us assume that the cause of our sense ideas is an intellectual creature (an angel or a demon). In such a case, our mistakes could not be imputed to God, but to our rushed judgements - judgements that we are able to withhold. But, even assuming that the cause of those ideas is God, this wouldn't make of Him a deceiver (fallax), since our great propensity to believe that they come from physical objects is not a clear and distinct perception, but a psychological compulsion that, when reflecting, we are free to ward off. All this suggests that Descartes' argument contains a clear and distinct perception, and that the content of that perception is that intellectual natures, whatever they may be (myself, an angel, or God), cannot be the cause of sensory ideas (understanding 'sensory ideas' in a very restricted sense that it will be unpacked when developing the problem of ideas that are materially false). If this is so, Descartes' appeal to the veracity of God is either a red herring or at most a supplement to the proof itself. That Descartes had dissimulated on this issue is easily understandable, either because he consistently avoids expressions suggesting limitations of God or because of the metaphysical consequences of fleshing out his insight.

${ }^{13}$ On the teachings of nature, and the difference between them and the deliverances of the natural light, see AT VII 81-3 / CSM II 56-8.

${ }^{14}$ It would seem worth exploring the analogies between the Cartesian notion of "the teachings of nature" and the Wittgensteinian concept of "hinge beliefs" (however, I'll say later something that, locating the similarities between the Cartesian proof of the external world and Wittgenstein's hinge epistemology at a deeper level, discourages this specific line of research). Besides, it is interesting to notice that the three components that, according to Thomas Reid, make a perception (in contrast with a mere sensation), that is, "some conception or notion of the object", "a strong and irresistible (...) belief of its present existence", and the fact that this

Análisis. Revista de Investigación filosófica, Vol. 2, n. 1 (2015): 163-193 
Finally, Descartes nails the latter point down when appealing to the veracity of God. His point is that, since rational deliverances have been successfully selfvalidated, the silent approval of reason is the equivalent of an indirect validation of our basic beliefs. Once the last authority of reason has been warranted, the possibility that our compulsive and natural 'beliefs' could be false no longer makes sense.

There is much to say for the previous reconstruction, much more nuanced than common caricatures of the Cartesian proof. ${ }^{15}$ However, this should not blind us to the fact that it is far from convincing. There are at least three kinds of problems with this approach. The first group of problems concern the internal structure of the proof itself. In the first place, some parts of the proof, specifically, the supposed appeal to the involuntariness of sensations, are superfluous on this reading. After all, wouldn't it be sufficient to invoke the teachings of nature to reach the desired conclusion? If so, there is a mismatch between this version of the argument and Descartes' strict conception of logical validity, which rules out as formally invalid arguments containing a redundant or a useless clause. ${ }^{16}$ Given the highly structured nature of the Meditations, that mismatch militates prima facie against the standard account. The second shortcoming concerns the use of the teachings of nature as a step of the argument. It is not only that Descartes makes no explicit mention of this allimportant notion throughout the proof (he simply appeals to "a great

belief is "immediate" (REID 1941, p. 79), do possess unmistakable Cartesian resonances: a point that we should keep in mind in order to abstain from ascribing to Descartes the same doctrines of his empiricist successors.

15 It is not as if Descartes were trying to gain access to the external world only from sensations. As Reid and Frege aptly noted, the private nature of sensations would make this procedure logically unfeasible. Consider the agreement between Reid and Frege on this point:

"(...) for no sensation can give us the conception of material things, far less any argument to prove their existence" (REID 1941, p. 156). [This text contains another Cartesian resonance: the doctrine that sensations are materially false, namely, that they have either no content at all or an opaque content. On this important point, we will elaborate later.]

"Having visual impressions is certainly necessary for seeing things, but not sufficient. What must still be added is not anything sensible. And yet this is just what opens up the external world for us; for without this non-sensible something everyone would remain shut up in his inner world" (FREGE 1997, p. 343).

${ }^{16}$ This is one of the main traits of Descartes' antiformalism in logic, a trait that he borrows from the Pyrrhonian dialectics against the Stoics' inference schemata, and that plays a conspicuous role on his dispute with Gassendi about the non-inferential nature of the cogito. For a detailed analysis of Descartes' view about formal validity, see CURLEY (1978, pp. 30-4). 
propensity to belief' [AT VII 80 / CSM II 55], and this seems rhetorical), but that, as Descartes himself makes clear, this concept only applies to nature "in (a) limited sense", namely, to "the combination of mind and body" (AT VII 82 / CSM II 57), and so to those convictions whose content is unintelligible from a rational perspective. It would go against all the rules of logic to invoke the rationally opaque teachings of the composite's nature to contrive a rational proof whose starting point is the sceptical mind, a mind that at this point of the Meditations ignores not only whether it is attached to a body, but whether it is intermingled with it. To conclude, this interpretation makes difficult to make sense of a passage almost immediately prior to the proof in which Descartes explicitly warns about calling upon natural impulses whose epistemic value is dubious. ${ }^{17}$ Moreover, if the teachings of nature were the crux of the argument, it would be up to a Berkelian to remind Descartes of his own doctrines, namely, of the fact that many things that seem "teachings of nature" really are "ill-considered judgements" (AT VII 82 / CSM II 56) solidified by habit and neglect, and so to cast doubts upon their epistemic status. This indicates that the teachings of nature are a non-starter, and that, unless the proof hinges on purely rational considerations, it is lacking the demonstrative standing to which it aspires. ${ }^{18}$

17 "I reckon that a great deal of confidence should not be placed in what I was taught by nature" (AT VII 77 / CSM II 53).

${ }^{18}$ One could say that instead of replying to the Berkelian qualms we are displacing them to a lower level. After all, and whatever may be the nature of Descartes' proof of the external world, the fact is that he appeals to the teachings of nature in order to warrant the substantial union, the correct functioning of the composite (to attain welfare), and the general match between sensations and the objects they (obscurely) represent. Berkeley's devastating questions legitimately reappear at this level, and with them the possibility of disconnecting our rational framework from what apparently are common sense beliefs, depriving the latter of any sort of rational support (including a default rationality).

On this issue, it should be enough to remember that Berkeley's whole case depends on his thesis that a material substance in unintelligible. As it will be discussed later, the main point of the Cartesian proof is to demonstrate that without a material substance our capacity to think particular objects or states of affairs would be impossible, and so that external objects are required in order to explain some of our mental activities. If Descartes is right, the teachings of nature are not exposed to Berkeley's attack. Notice, however, that they only can fulfil an epistemic role after the proof of the external world, a proof that they are unable to provide, and that must be based on elements that, contrary to sensations, impart a clear and distinct conception of corporeal things. 
Further problems arise from the isolated nature of the proof afforded by this widely accepted account, namely, from the fact that, abstracting from the methodically organized background whose upshot is a highly compressed argument, this reading deprives itself of evidential support, it is by its own nature blind to some puzzling questions instrumental to clarify Descartes' meaning.

The most significant of those questions are: (i) Why, rather than tackle the issue without further ado, does Descartes involve himself in a detailed discussion — the famous chilliagon passage (AT VII 72-3 / CSM II 50-1) — of the differences between pure understanding and imagination? Is he procrastinating or preparing the ground for the argument? (ii) Why is the first attempt to demonstrate the existence of material things, an attempt based on the mind's power to imagining, a failure? What are the lessons learnt from this defeat and how they help to redirect Descartes' procedures? Could this failed demonstration be used under further conditions, that is, could it, once the epistemic position of the Meditator is rectified, replace the proof from sensory perception without loss? (iii) Is it significant that the argument for mind-body distinctness immediately precedes the proof of the material world? If so, how does Cartesian robust dualism contribute to bridge the gap between the internal and the external? (iv) Why does Descartes put an end to the argument stating that what has been proved is "that corporeal things exist", and that "at least they posses all the properties which I clearly and distinctly understand, that is, all those which $(.$.$) are comprised within the subject-matter of pure$ mathematics" (AT VII 80 / CSM II 55)? Is this passage an echo of a wellknown text from the First Meditation (AT VII 20 / CSM II 14)? Is Descartes limiting the scope of the proof? And if this is so, are those limits fixed by the understanding or by phenomenal sensation, by a purely cognitive way of being aware of the material world (the kind of awareness proper of a res cogitans attached to the human body or of a thinking thing present in the body "as a sailor is present in a ship" [AT VII $81 /$ CSM II 56 $]^{19}$ ) or by feelings? Are the

${ }^{19}$ Descartes raised the same possibility under a different description, that of an angel externally related to a body, in a letter to Regius dated on January 1642 (see AT III 493 / CSMK III 206). The very fact that Descartes provides a conceptual niche for this sort of external or accidental relation militates against hylomorphic renderings of his philosophy of mind, those which, projecting Aquinas to Descartes, make of the human body something incomplete, that has to be actualized by the mind, and of the mind, considered in isolation, something intrinsically related to a particular body. 
properties represented by phenomenal sensation clear and distinct, or rather obscure and confused? The replies suggested by those questions help to make sense both of why Descartes does not appeal to the teachings of nature to develop his argument and of the unequivocal gap (a change of issue) that separates the argument for the external world from the following discussion on sensation and the substantial union.

Finally, this reading takes too much for granted, in particular, it takes for granted that when distinguishing a lax and a restrict meaning of "having a sensory perception" Descartes is slicing off the what-it-is-like aspect of experience. Nevertheless, there is an alternative view on Descartes' meaning, one that underlines that he is not separating the bodily dispositions which are usually associate with sensations from qualitative sensations, but separating qualitative feelings from the reflective awareness of those feelings, namely, from the indubitable fact that, although it could be false that I am seeing a green patch or feeling a toothache, it still seems to me that I am seeing one thing or feeling the other. Those seemings are thoughts from which I cannot detach myself, formal acts of thinking as invulnerable to the hyperbolical doubt as the cogito itself. Their contents (that I am undergoing such and such affection, that I am seeing this or that item...) could be false, and yet it couldn't be false that I am thinking (considering, believing, doubting...) about such an experience. Notice that that which could be false is not only that I am seeing a tree (in contrast with merely having a hallucination of a tree), but that I am having whatever sort of phenomenal experience, veridical or not. Notice too that Descartes invariably distinguishes sensation from perception, meaning by the latter "a perception of the intellect". In this way, the narrower thinking that remains from this exercise of disambiguation is completely intellectualized, at the same time that, inasmuch as phenomenal contents are its subject matter, it is credited as sensory perception, understanding this latter term not as a sensorial mode of presentation (how things and properties are sensorially presented), but as a range of propositional attitudes applied to thoughts whose content is the phenomenal character of experiences. This reading seems better suited to at least three aspects of Descartes' philosophy: his radical doubt (seriously taken), his description of sensory perceptions as modes of thinking, and his stringent 
and technical use of words such as 'perception' and 'ideas' (including the ideas of sense)..$^{20}$

The unpacking of Descartes' distinction is, however, much more complicated than what is suggested by the previous account. As a matter of fact, this is a conceptual knot that, due to his immersion into the senses, the Meditator is not up to disentangle in a significant fashion until well into the Third Meditation. My guiding question is: Is the strict meaning of "having a sensory perception" invariant, or rather, that which the passage from the Second Meditation provides is a provisional distinction commensurate to a particular standpoint, a distinction which gestures to the right direction of enquiry, but which has to be widened? And if the latter is so, why cannot the former view be Descartes' last word on the issue? I am confident to identify the sceptical pressure that compels Descartes to move a step further. ${ }^{21}$

\section{THE IDEAS OF CORPOREAL THINGS: A REDUCTIVE ANALYSIS}

In a groundbreaking article on Descartes' use of skepticism, Deborah Brown (BROwN 2013, p. 25-42) argues that what marks Descartes' departure from Pyrrhonism is an unparalleled and radical version of content skepticism, to wit, a kind of semantic skepticism whose main (but by no means the only) target are sensory ideas. Let us consider sensory ideas as explained above, that is, as thoughts whose contents are phenomenal: thoughts about sounds, colours, pains, etc., or, alternatively, thoughts about hearing sounds, seeing colours or feeling pains. Is there any problem with this sort of thoughts?

For a start, phenomenal content would make a genuine and categorial distinction between thinking and sensing all but possible, and so it would undermine the general skepticism regarding experiences to which Descartes'

\footnotetext{
${ }^{20}$ Descartes is eager to distinguish ideas from images, and to stress the propositional and conceptual character of the former (closely related to the pure understanding). Among many other texts, see the definition of 'idea' in the synthetic exposition of the Second Set of Replies (AT VII 160-1 / CSM II 113), or the harsh discussion with Hobbes on this point (AT VII 181 / CSM II 129-30).

${ }^{21}$ This reading is conditional to a serious interpretation of Descartes' sceptical worries. I am aware that sceptical readings of the Meditations have been unfashionable for a couple of decades. But, besides the unacceptable consequences of wiping out this trend of Descartes' thought, it seems that this fashion is becoming outmoded. See, as an example, the recent monograph by WAGNER (2014), or the current controversy involving FINE (2000), WILSON (2005), or BROWN (2013), on the relation between Cartesian and Ancient skepticism.
} 
external stance towards sensations points. Put another way, even if one doesn't know whether a particular phenomenal proposition (propositions whose contents are subjective experiences: that I am feeling cold...) is true, one seems able to grasp under which conditions it would be true, namely, to grasp the meaning of those items described as "suffering pain", "seeing a blue patch", "feeling cold", and so on. In this way, content dogmatism (the view that truth conditions of sensory experiences are unproblematic) and token-to-token experiential skepticism are compatible. Nevertheless, content dogmatism presupposes that, insofar as the ultimate source of phenomenal content has to be experience itself (direct acquaintance with, say, the phenomenal character of the experience of red), most of our experiential beliefs are correct. This means, in turn, that phenomenal sensations cannot be completely externalized (from propositional thinking about them), and so that it is not possible a logical severance (in contrast to the accidental and the empirical) between the indubitable fact that I am thinking about a phenomenal content and the phenomenal experience on which I am thinking. Sensory ideas and phenomenal experiences are logically interrelated, and so they stand or fall together.

That Descartes thought that they fall together is a point that the discussion on the material falsity of sensory ideas (AT VII 43-5 / CSM II 29-31) helps to make clear, a discussion where both acts of thinking and objects of thought are severely restricted.

Ideas of what Locke would later call "secondary qualities" are materially false insofar as they "represent non-things as things" (AT VII 43 / CSM II 30), and so "provide subject-matter to error" (AT VII 231 / CSM II 162). A way of unpacking Descartes' meaning is by pointing to the kind of error he has in mind, and then by providing an account on the sources from which that error stems. The error in question is the common tendency to think that sensations represent positive properties of bodies that resemble their phenomenal character, namely, that 'pain' or 'coldness', understood in terms of experience, and not in terms of extension and movement (as "leg's damage" or as "a slow movement of particles") are (or could be) positive properties of corporeal items. This is for Descartes a categorial error, one that involves projecting into the physical realm psychological aspects that are inherent to experience, thus blurring the distinction between how information is presented to a sentient being and a reductivist view of physical properties. Corporeal properties have to be 
explained in terms of corporeal notions, a point which rules out an understanding of the physical world in terms of irreducible phenomenal 'properties'.

However, this is only part of the story (and a part that Descartes downplays when bringing material falsity to focus). It is not only that sensory ideas cannot be applied to a particular domain, but that they are opaque, namely, that they do not provide an intelligible notion or conception of the items that they presumably represent, a notion that could help a rational or discursive being to recognize and identify them. Notice that, instead of misrepresenting objects, sensations represent "non-things as things," namely, that they do not represent at all (or, at least, that their objective contents are so elusive that by inspecting them we cannot know what, if any, is the reality that they represent, or, ceteris paribus, that they are). In this sense, the source of the aforementioned error is not so much a categorial mistake as an illusion of contents and of possible (conceivable) realities: the illusion of thinking that we understand something (experience and its modes) that, being intrinsically elusive, cannot be conceptually approached, and, of course, to make of a realm opaque to propositional thinking the very model of understanding! Deprived of "objective reality", or, in other words, of an intelligible content that we could verbally pinpoint and share, that could mirror or be mirrored by something apart from unordered experience itself, qualia cannot be objects of (rational) thinking: Mary, in her black and white laboratory, could have a perfect understanding of what physical pain is without ever having felt it. ${ }^{22}$ For Descartes, it makes no sense to ask what kind of properties phenomenal properties are.

It is curious to notice that, when approaching the problem of ideas materially false, most interpreters raise this issue from the perspective taken by Arnauld in his criticism of this Cartesian notion, ignoring both that Descartes would accept Arnauld's critique if what he meant were what Arnauld took him

\footnotetext{
22 This does not make of Descartes an epistemic eliminativist, that is, a dogmatic philosopher who thinks of the limits of the understanding as the very limits of reality. On the contrary, pointing to a realm irreducible to rational understanding, Descartes fixed the possibilities and the limits of his rationalism. Curiously enough, those limits are not (up to a certain point) in the domain of conceptual and universal thinking, but in the domain of nonconceptual and particular experience. On the other hand, the case of Mary, so relevant in the contemporary philosophy of mind, is paralleled by the Cartesian example of the res cogitans in the machine.
} 
to mean, and that the point of Descartes' reply was to show that Arnauld didn't really understand his doctrine. ${ }^{23}$

Arnauld is concerned about the formal dimension of ideas, namely, about the fact that they are ideas of something, that they have a specific content. His point is that, since every idea must have a positive content which is independent of whether it refers to a positive property of things or not, from the fact that the idea fails to refer it does not follow that the idea of, say, cold, is false, this meaning that it lacks a positive content. Lack of reference does not entail lack of content. Moreover, to have an idea implies to have a positive conception of something, and so it makes no sense to consider the possibility of ideas without content, of ideas of nothing at all. ${ }^{24}$ For Arnauld, to have a false idea of cold is equivalent to have a false conception of what it is for a physical item to be cold, that is, it is to refer an idea that represents something "real and positive to me" (AT VII 207 / CSM II 145) to something that does not correspond to that content. It is not thus the content what is false, but the judgement that this idea is a correct representation of a physical item. This is why Arnauld accuses Descartes of confusing judgments and ideas, a charge that could be rephrased by saying that he (Descartes) confused the representational value of an idea with its intentional content, the "of" of reference with the "of" of intentionality, seeing a failure in representing as a sharp decrease in meaning.

That the previous view cannot be attributed to Descartes is something borne out by the philosopher's insistence on making clear that he is not taking ideas formally, as "representing something" (AT VII 232 / CSM II 163), ${ }^{25}$ but

${ }^{23}$ This is why Descartes says that "instead of meeting him head on I will dodge his blows," insisting that "when I wrote what I did, I meant it in another sense [than Arnauld's]," and accusing Arnauld of concentrating "on ideas taken in the formal sense" (AT VII 231 / CSM II 162).

${ }^{24}$ In order to be subjects of predication ideas have to have a positive content. In this way, Arnauld reads Descartes as rejecting the very ground that makes possible to predicate of sensory ideas their "falsehood". This predication would undermine its very conditions of possibility, being self-stultifying or self-refuting.

${ }^{25}$ Notice the ambiguity of the expression "as representing something". This could be read as Descartes saying that he is not taking ideas "inasmuch as they have content" (the content that the idea presents to me) or, alternatively, that he is not taking them "insofar as they refer to an external item." Since it is content that makes (successful or unsuccessful) reference possible, both senses are logically related. Anyway, in reversing Arnauld's perspective Descartes is suggesting that he does not accept the two main theses attributed to him by his opponent: that 
materially, as acts of thinking or "operations of the intellect" (AT VII 232 / CSM II 163). When saying that the idea of cold is materially false, Descartes' meaning is not that its content is false, that it falsely represents what physical coldness is, but that there is no content, and so that it is a false act of thinking, namely, that we think that we are thinking (understanding, conceiving...) something, when in fact we are having a sensation. The whole point of Descartes is that having a sensation is not thinking about something, and so that there is no idea of cold. In other words, Arnauld reads Descartes as explaining the lack of content in terms of lack of reference, when Descartes' explanation moves in the opposite direction: it is because sensory ideas do not have a positive reality (we do not know what they are) that they fail to represent or to misrepresent (in this context both predicates would be nonsensical: there is no content which could hit the target or fail to do it). Sensory ideas do not present something "real and positive to me": this is why they are not ideas, something quite different from saying that they are ideas without a positive content. ${ }^{26}$ Thus, Arnauld misses both points: Descartes' motivation and Descartes' meaning.

This view is further substantiated by Descartes' appeal to the ideas of God "which are concocted by idolaters" (AT VII 233 / CSM II 163), that is to say, to concepts whose contents are contradictory. Those ideas could also be called "materially false". Descartes' point is that when taking ourselves as thinking contradictory concepts we are confusing a simulacrum of thought, a mere verbal activity, with a real act of thinking, with a real operation of the understanding. Insofar as contradictory ideas are deprived of an intelligible content, we are unable to think them, and so they are not ideas at all. Intelligibility, that is, perception by the intellect, is the mark of ideas, a mark that contradictions miss

he presupposes that sensory ideas do have content (and so, that they are ideas), and that the problem he is dealing with is that of misrepresentation.

${ }^{26}$ Notice that Descartes is quite explicit on the above points. On the one side, he says that "whether cold is a positive thing or an absence does not affect the idea I have of it, which remains the same as it always was" (AT VII 232 / CSM II 163), making clear that he is not dealing with the idea's failure to refer. On the other side, he points to his real worries (the conceptually elusive nature of experience) when saying that "if I consider the ideas of cold and heat just as I received them from my senses, I am unable to tell that one idea represents more reality to me than the other" (AT VII 232 / CSM II 163). Notice that the problem is what reality, if any, a sensory idea represents to me, not what external reality, if any, it represents. Descartes casts the issue in terms of sinn, not of bedeutung. 
due to a formally defective union of positive contents, and sensations miss due to their opacity. The important point is, however, that contradictions and "sensory ideas" are related as simulacra of thinking, or, alternatively, as simulacra of meaning, that they belong to the same genus of fake intellectual operations.

Notice too that, for Descartes, our ideas are not separate items enjoying a kind of semi-independent mental existence, quasi-things that populate the transparent realm of the mind, and that are the privileged candidates of apprehensive and thinking acts. By 'idea' Descartes means "the form of any given thought" (AT VII 160 / CSM II 113), which in turn means that the idea cannot be separated from the act of thinking it, that we are aware of our ideas in so far as we are aware of the activity of thinking them. The outcome is that there is no residual thinking of an idea if the idea is unintelligible. Sensations cannot be objects of thought, and so they are deprived of the certainty that thinking provides to its objects. The whole notion of phenomenal ideas collapses. ${ }^{27}$

The upshot of Descartes' analysis is that the only sensory ideas properly so are ideas of primary qualities, namely, ideas whose contents (size, extension, shape, position, movement, duration and number...) are transparent to the pure

\footnotetext{
${ }^{27}$ Interpreters have mainly focus on the issue whether sensations intrinsically misrepresent their objects or whether sensory misrepresentation is due to extrinsic features, namely, to erroneous judgments based on phenomenal items. Descartes is keen to underline that sensations are not a guide to truth, that "no falsity can occur in them" (AT VII 438 / CSM II 298), that is, that they are not truth-bearers, and that they play a functional role in the welfare of the individual, stressing so that sensory misrepresentation must be understood in terms of harsh judgements or misleading conceptions that "we formed without any reflection in our early childhood" (AT VII 438 / CSM II 295) and that we are able to correct.

The curious thing is that both parties have thought that the problem of ideas materially false bears on this issue. It is thus important to distinguish the point of Descartes' doctrine: that sensations provide no intelligible access to the world, that they fail to represent something to the intellect, from the separated topic (addressed in the second half of the Sixth Meditation) of what, how and why sensations represent in the context of the substantial union. The latter issue is explicitly circumscribed by Descartes to a domain beyond the pale of pure understanding, and so it makes sense to state at the same time that sensations do not represent at all (to the intellect), that they represent (clearly) physical items (to the sentient ego), and, inasmuch as they are non-epistemic in character, that they do not inherently misrepresent their objects. That sensations are not guilty of common errors is illustrated by the cases of the amputated leg and the man with dropsy, where errors result from a bad reading of the situation (a deficient understanding of the context), and not from sensations.
} 
understanding. ${ }^{28}$ Descartes' suggestion is that we only can make sense of something in terms of primary qualities, that to entertain a possible physical reality is to understand its position in a spatiotemporal domain. Notice, however, that this understanding is conceptual and propositional, that it doesn't require any sort of visual imagery, either austere or phenomenally loaded. None succession of images constitute the process of thinking about something. Images are at most features accidentally attached to thinking. One can understand that a thing is to the left of the table or that two items are really the same without having to evoke 'mental' pictures of the situations so described. What marks the difference between visual representations involving primary qualities and sensations is that in many cases the former, but not the latter, are a suitable medium to convey thought, to wit, that the ideas conceived but the intellect can easily be represented in this format. But the medium is not the message. Moreover, given the possibility of understanding particular situations without images, the strict distinction between ideas (intellectual acts) and visual presentations, and the fact that pictures are not by themselves acts of thinking (they do not contain their own meaning), but items that can manifest, convey or be accompanied by thought, it is imperative for Descartes to separate sensory ideas from any sort of experience. ${ }^{29}$

Notice too that Descartes is talking about particular acts of thinking, about our understanding of particular items or situations as such and such, as with a concrete size, position, duration, essence or identity. At the end of the day, with "sensory ideas" Descartes means the recognitional and interpretative power of the mind, he points to thoughts that are exercises of intelligence, to intellectual actions that might be performed good or badly, with or without

28 They are things that the Meditator "perceive(s) clearly and distinctly" (AT VII 43 / CSM II 30).

29 The objects of understanding are wider than the objects of representation. It is thus worth to underline that the genus of intelligible/conceivable objects could be divided, depending on whether they can be visually represented and on their possible modes of representation, in three sub-groups: (i) God, the self, and the common notions are intelligible but not representable; (ii) the essential relations that constitute mathematical objects can be represented in a spatial vacuum (without including the position of an empirical self); (iii) particular items only can be represented in a self-centered space and time. Empirical imaginings are a special case: they are not given in a vacuum, but they don't depend, unlike perceptions, on the actual corporeal position of the imagining person. In any case, Descartes relates the spatial vacuum of abstract mathematical representations to the faculty of imagination. 
success. They are different from clear and distinct perceptions, which taken by themselves are not actions, but direct and immediate apprehensions, passive mental states that couldn't be described with sense as 'intelligent' or 'stupid', 'successful' or 'unsuccessful'.

In the strictest sense, "having a sensory perception" boils down to these fully-intellectualized thoughts that, defining the very limits of the indubitable self, are the only starting point possible for a proof of the external world.

Several important elements emerge from the previous discussion.

For one, a suitable starter that conforms to the stringent criteria imposed by radical scepticism and whose contents are shareable and objective.

In second place, a well-grounded distinction between two different powers of the intellect: the intuitive capacity of the mind to apprehend the necessarily connected attributes of items for which there are no sensory correlates and whose intelligibility is, besides independent of a representational or relational framework, either unsuitable to any kind of representation (the self, God, common notions) or suitable to abstract representation (a kind of representation where there isn't a particular spatial relation between the image and the subject's body); and the understanding of particular items, which is corrigible, context-dependent and suitable to visual representation, meaning by the latter that, although we understand those items without the help of

\footnotetext{
30 This does not entail that the intellectual process culminating in clear and distinct perceptions could not be described as an active and intelligent performance. The point is just that we cannot either fail to understand or understand only up to a certain point intuitive necessary relations, that in the case of intuitive knowledge there is no gap between the items we perceive and our perception of them. The distinction between states and exercises of intelligence, so prominent in the current debate between intellectualists and anti-intellectualists on knowinghow and intelligent action, sheds light on Descartes' analysis of the twin abilities of the mind. Nevertheless, my opinion is that contemporary paradigm cases of states of intelligence, such as entertaining the thought that the number of the stars is odd, would be considered by Descartes as exercises of understanding, as intellectual performances that, inherently partial and relative, could be corrected or re-interpreted. He would reserve a complete, and so a passive understanding, to intuitive apprehensions. Note, by the way, that I am talking about a complete understanding (where "complete" is a qualitative adjective which refers to a firm or invulnerable apprehension), something compatible with an inadequate knowledge (a term which, together with its opposite, refers not to the quality, but to the extension of knowledge: adequate knowledge is all-inclusive, inadequate knowledge is partial and unfinished), a knowledge that falls short of the divine. Contrary to common views, Cartesian certainty and epistemic humility are not incompatible: we don't get a firmer grasp of the Pythagorean Theorem by extending our understanding of the nature of the triangle.
} 
imagery, they are objects that could easily be represented within a self-centered space and time, in an empirical concretum that, as focal points, insert us into space and time. So, in a sense, particular understanding seems to require a positioned and embodied mental operation in a way that both intuitive perceiving and mathematical imagining do not. It is thus imperative to provide an account of this highly peculiar intellectual power, irreducible to the pure understanding of essential and universal relations. The quest for an appropriate explanation of this indubitable intellectual ability will establish the bridge to the external world. ${ }^{31}$

Finally, a clear awareness that the only obstacle that prevents an inference from the mental fact that we entertain particular thoughts to the condition that makes this power possible, is that those ideas might have been produced by some unknown power of the mind, that is, that "it seems possible that they are contained in me eminently" (AT VII 45 / CSM II 31). Overcoming this sceptical possibility requires stripping the self of accidental features, in such a way that the essential operations of the mind are constitutively unable to explain our thinking of particular items. If in its strictest sense the mind is incapable to produce those thoughts by itself, the certainty pertaining to them will contain something else than the mind itself.

These are the three building blocks from which Descartes construes the proof of the Sixth Meditation. It is curious to notice to what extent Frege and Descartes shared intuitions on this point, how smoothly Descartes' argument fits into Frege's description of the form that a proof of the external world should take. These are words that could easily be put in Descartes' mouth:

So perhaps, since the decisive factor lies in the non-sensible, something nonsensible, even without the co-operation of sense impressions, could also lead us out of the inner world and enable us to grasp thoughts (FREGE 1997, p. 343).

\section{THE OBJECTIVE NATURE OF HUMAN SENSE PERCEPTION.}

\footnotetext{
${ }^{31}$ Descartes introduces this second power of the mind in the wax passage at the end of the Second Meditation. As a matter of fact, the main purpose of that controversial text is to bring this recognitional power to the attention of the Meditator, as Ben Mijuskovic forcefully argued in a much-ignored masterpiece: "Descartes's Bridge to the External World: The Piece of Wax". See MijusKOVIC (1991, pp. 312-28).
} 
Now we should be able to pull the several strands of our discussion together.

Two salient points in the remarks antecedent to the Cartesian proof are both the distinction between the power of understanding and the powers of mathematical imagining and of having sensory perceptions, and the epistemic and logical primacy accorded to the former power, which is the independent logical ground for the latter powers. ${ }^{32}$ Notice that Descartes cast the discussion in terms of powers, capacities or faculties, and that, although different from, to anticipate, pure understanding, imagination and sensory perception are of the same category: they are special modes of thinking, to wit, modes of understanding delimited by the very nature of the thinking substance and which include "an intellectual act (...) in their essential definition" (AT VII 78 / CSM II 54). This substantiates our claim that pointing to a distinctive "power of understanding" Descartes is demarcating, not an abstract universal, but pure understanding, namely, unconditional understanding or understanding under tautological conditions, this meaning the sort of innate understanding that the Meditator has learnt to exercise from the cogito argument and whose objects (God, the self, the intuitive principles of logic, etc.) are constituted by essential aspects that the mind pulls from within itself, without further pre-conditions or requirements to make use of it. The self-presentation of the cogito, independent of how the world is or even of whether there is a world, the understanding of an unconditional ground for possibilities, independent of what contingent possibilities, if any, have been actualized, or the understanding of the necessary attributes of mathematical figures, independent of whether they exist or not, are prominent examples of a kind of understanding ${ }^{33}$ that, making facts intelligible, is not based on any fact (or information) whatsoever. ${ }^{34}$

How to describe the relation between pure understanding and the two special modes of thinking? One option would be a conceptualist reading which, making of the thinking substance nothing else than the collection or addition

\footnotetext{
32 See especially AT VII 73 / CSM II 51, and AT VII 78 / CSM II 54.

${ }^{33}$ A kind of understanding that, although detachable and independent, constitutes a necessary condition for all ways of understanding, and so that it is a constitutive ingredient in all the possible operations of the intellect.

34 Notice that the simple present tense in which those acts of thinking are expressed (the "I think" of the cogito argument) does not indicate a unique moment that could be identified (and re-identified) within a temporal framework or under some description. On the contrary, it singles out a moment that dangles in a temporal void, an indefinite and detached present.
} 
of its modes (GLOUBERMAN 1991, pp. 363-84), would contend that unconditional understanding is another mode of understanding, and that the genus understanding is but an abstract noun which, referring to no concrete power, singles out a particular series of related but different operations. An alternative reading would preserve the robust asymmetry between substance and modes so prominent in Descartes' metaphysics, and, availing itself of the distinction between determinables and determinates to shed light on the logical relations of a substance with its modes, would think of understanding as the undetermined essence of the mind, an essence determined by its modes (including unconditional understanding).

Those two interpretations cannot be, however, correct. On the one hand, Descartes explicitly emphasizes that imagination and sensory perception are modes of understanding, and so that understanding is the essence of the mind (and not another mode). On the other hand, understanding is a distinctive, determined and specific power, independent of imagination and sensory perception. The problem is to make sense of both claims. Making a substance of understanding, the first claim pulls us to see it as a determinable. Modelling it as a distinctive power, the second claim invites the reader to see it as a kind of understanding, namely, as a mode. The problem is how imagination and sensory perception can be modes of unconditional understanding when they are not performances or examples of this power.

On dealing with this topic, Descartes' approach is rooted in a Neoplatonist model, something that, by my lights, does not make it unfamiliar or farfetched. Descartes' point is that this is an asymmetrical relation such as the concept of unconditional understanding does not include the understanding of particular items, but the concept of the latter includes and integrates the former. In this sense, unconditional understanding grounds, but not exhausts, other ways of understanding. Put another way, all the operations of the intellect presuppose and include the logical framework that is the intentional object of pure understanding, and that make their objects intelligible. Thinking an item is thinking a set of norms that govern, constrain and make possible the understanding of all the appearances. Particular thinking goes accompanied with an implicit understanding of nomological facts, an understanding that methodical reflection makes explicit. This continual thought is the enduring subject/act of changing thoughts, the substance that determines and permeates the range of its modes. If Descartes highlights the distinctive nature of unconditional understanding is to emphasize the gap between the logical 
framework valid for all possible worlds and the understanding of states of affairs that, besides the former, requires another normative scaffolding whose contents neither can be derived from the basic principles furnished by unconditional understanding alone nor are to be found or observed among the particular aspects of sense experience. It is this unbridgeable gap, combined with the fact that, according to Descartes, neither imagination nor sensory perception constitute "the essence of the mind" (AT VII 73 / CSM II 51), namely, that unconditional understanding is a power that, by itself, is able to define a complete substance, ${ }^{35}$ what makes possible for Descartes to conclude both that pure intellectual substances alone cannot explain understanding of particular items and that this power is essentially and constitutively related to the physical world. Based on a set of considerations whose ultimate ground is that the notion that we can have powers based on nothing is senseless, the Cartesian proof is far from negligible. ${ }^{36}$

35 "Now I can clearly and distinctly understand myself as a whole without these faculties [imagination and sensory perception]...” (AT VII 78 / CSM II 54).

I would favour an epistemological, and not an ontological reading of this claim. Unconditional understanding defines the basic structure of a substance, but it does not say anything about how this structure is or could be instantiated. Clear and distinct perceptions are always true of something, but the nature of its truth-maker varies whether considered in isolation or considered in context. In other words, logical independence does not entail ontological isolation. This is, however, compatible with a robust empirical and conceptual dualism.

${ }^{36}$ Why does not Descartes cast the proof in terms of mathematical imagination? Why is not this power able to provide the basis for a demonstrative proof of the existence of the body, and only furnishes a probable conjecture? In my opinion, there are at least two reasons that make of abstract imagination a non-starter. Firstly, mathematical imagination is the visual representation of the deliverances of the pure understanding of the necessary attributes of geometrical figures, which means that the necessities that imagination represents are nothing else than the unconditional necessities grasped by the pure intellect, and so that the very limits of the latter are inbuilt in imagination (after all, the existence of the physical world cannot be deduced from logical principles alone). Whether or not there is a physical world, those necessities are true of something. Certainly, it seems more probable to think of geometrical essences as structural features of the extended substance, and so as truths whose truth-maker is the physical world (at the end of the day, this is Descartes' position on the disputed topic of the ontology of possibilia). The problems are that the limited standpoint of the Meditator at this point leaves more options open (essentialism), and that the physical world to which geometrical properties would give access is far too austere and indeterminate. In second place, and insofar as imagination is visual, it does conform neither to the stringent criteria set by radical scepticism nor to the propositional understanding which fixes the range of the indubitable self.

Análisis. Revista de Investigación filosófica, Vol. 2, n.o 1 (2015): 163-193 
Notice, however, that the crux of the argument lies in a groundbreaking extension of rationality that adds unexpectedness to novelty, ${ }^{37}$ and so that the proof parallels with different contents the same procedure that in the Fifth Meditation made possible to support the objectivity of essential relations.

Descartes' point is that to be understood particular items have to be located within a net of necessities beyond the realm of abstract logical principles, necessities that the mind is incapable to reject and so that we grasp as the limits that regulate the understanding of the appearances perceived by the senses. Necessary principles such as causal sequentiality, 'sameness' (identity through change), regularity of change (things cannot pop in and out of existence), indefinite and continual temporal succession, etc., govern and enrich the scarce data provided by the senses: they are the mental ingredient of human experience, namely, of experience that conjoins intellectual agency with sensory awareness, and so that is inherently objective. These are the "fundamental principles of human enquiry" (WITTGENSTEIN \ 670), ${ }^{38}$ principles that are activated, but, unlike what happens in the Aristotelian model of abstraction and sensory transmission of rules and universals, not conveyed by the senses, that, unlike facts, are not explicitly taught, and that, inasmuch as they fix all possible experience, can be neither subject to testing nor confirmed by evidence.

That those principles conform to a physical world external to the mind is, for Descartes, secured by two considerations. Firstly, by a causal argument that points out that we could not make use of those principles unless they were activated or elicited by some mechanism or other to receive a flow of information from objects (sensory awareness as the paradigm case), that is, that understanding requires a raw material to which it applies. In second place, by an argument analogous to the one developed in the Fifth Meditation, where mathematical essences, insofar as they contain necessities and that some of those necessities are unforeseeable and so able to be discovered by the subject, give us externality. That the mind is incapable of rejecting the net of necessities regulating empirical appearances assures that they are not fictions, and so that they express objective and true norms, norms that are true of something.

\footnotetext{
${ }^{37}$ According to the common wisdom, is not the Cartesian philosophy the very paradigm of a minimal, restricted, and myopic conception of rationality?

38 This reference to Wittgenstein is far from idle. It seems to me that Descartes and Wittgenstein are exploring the same territory, extending the normative beyond the principle of contradiction, and wagging an attrition war in two fronts: against conventionalist interpretations of rules, and against empiricist reductions of them.
} 
However, and unlike geometrical essences, the only possible candidate to be their truth-maker is the physical realm they govern (after all, principles regulating experience are not prone to foster essentialist illusions): causal sequentiality and identity through change do not operate in a vacuum; to be true they have to relate some items or others. ${ }^{39}$ Externality is further substantiated by the fact that this immutable framework allows us to encounter and recognize particular identities and differences, and so to form with the help of sensory information illuminated by reflection a web of mutually limiting concepts, and to elucidate further logical relations among concepts, relations that are local or contextual. Logical limits are thus, in a sense, inexhaustible.

Curiously, on the topic whether a proof of the external world is possible or not, Descartes would align himself neither to Malebranche nor to Arnauld. ${ }^{40}$ Against Malebranche, he would contend that something else than revelation or faith is possible on this matter. Against Arnauld, he would point out that the argument is not based on God's veracity, and that at most this latter basis would warrant the argument at the meta-level, as it were, from a perspective external to the argument itself.

The picture of human sense perception that emerges from the previous discussion is that of a composite power that includes two discrete capacities working in tandem: sensory awareness as well as understanding. Facing the puzzle of how it is possible that, sensations being nonconceptual, the thought that I have a certain sensation is conceptual, and so the object of understanding, Descartes would say that, although the content of the thought that I am feeling a toothache is irreducible to the thought that there is damage in my tooth, it is the understanding of the latter situation, that is, the ability to recognize certain external criteria and patterns, what permits to identify my unsaturated sensation as a pain, and as a specific kind of pain, and so to sublate ${ }^{41}$ sensations into concepts that become embedded in a system of knowledge. Sensations are

\footnotetext{
39 This means that necessary relations do have an existential import, namely, that they have to be instantiated in order to be true. The objective truths of logic (in an extended sense of the word) are thus ontological indicators: a point that is consistently used by contemporary logicians (McGinn is only one case among others), and so that seems not too unreasonable.

40 See on this topic NADLER (1989, pp. 133-35).

41 This is the term used to translate Hegel's aufbeben. I have chosen this term because it integrates a negative sense (to abolish, to transcend) and a positive one (to preserve). The latter aspect fits well with Descartes' non-eliminativist approach to sensations. The former reflects the gap between phenomenal experience and understanding.
} 
only indirectly understandable. Transparent concepts (and so, public, objective, and necessary relations) do not come from private introspection. The idea is that, for Descartes, human beings, even if their minds are intermingled with their bodies or even if the exercise of the intellect is hindered by passions, never lose their thinking and reflective nature. Although this nature is not present in sensory awareness per se, it is constitutive of the construction of concepts and the epistemic agency that attend to it. On the one side, this means that Descartes is not obliged to deny sensory awareness to animals: lacking understanding, they are able to have a headache without knowing that they have it. ${ }^{42}$ On the other side, Descartes' point is that agency is present (as an attached factor) even in those cases where bodily cognitive mechanisms operate by default. This acquits him of the charge of suppressing the subpersonal, while settling a close kinship between his philosophy and contemporary forms of agential virtue epistemology, that is, of a virtue epistemology that makes of agency an essential ingredient of knowledge. ${ }^{43}$

The Cartesian argument could be encapsulated as «I think, therefore the physical world exists». We have argued that a robust conceptual dualism leads to a dimension of the mind with contains within itself the structure of the physical world, and so that it is constitutively related to it. One could thus say that an external and accidental relation based on the senses is consistent with an internal and necessary relation grounded on the understanding, that an empirical dualism is compatible with a transcendental union of mind and world. But unpacking the full implications for the metaphysics of mind of this thought would mean to reconsider Descartes' theory of modality and so to shed light on some of its neglected aspects.

Modesto Gómez-Alonso

Universidad Pontificia de Salamanca / The University of Edinburgh

modestomga@hotmail.com

\footnotetext{
42 Once we pay attention to the fact that, when advancing his doctrine of the three grades of sensation, Descartes is describing and analysing buman sensation, this reading fits well with his remark that only the physical aspects of sensation (the first grade of sensation) are common to animals and human beings. Inasmuch as the mind is intermingled with the body, the subject that perceives phenomenal sensation is the mind, something that does not happen in the case of animals and that does not entail that animals (animal bodies) do not feel sensations.

${ }^{43}$ Obviously, I'm thinking of Ernest Sosa, and his most recent version of virtue epistemology.
} 


\section{REFERENCES}

ADAm, C., TANnery, P. (eds.) (1964-76), Oeuvres de Descartes (I-XI), Paris: J. Vrin. BEANY, M. (ed.) (1997): The Frege Reader, Oxford: Blackwell.

BROWN, D. (2013): "Descartes and Content Skepticism", in K. Detlefsen (ed.), Descartes' Meditations. A Critical Guide, Cambridge: Cambridge University Press, pp. 25-42.

Cottingham, J., Stoothoff, R., Murdoch, D. (eds.) (1984): The Philosophical Writings of Descartes, Volume II, Cambridge: Cambridge University Press, 1984.

Cottingham, J., Stoothoff, R., Murdoch, D., Kenny, A. (eds.) (1991): The Philosophical Writings of Descartes, Volume III, Cambridge: Cambridge University Press.

Cottingham, J. (1991a): “Cartesian Trialism”, in G. J. D. Moyal (ed.), René Descartes. Critical Assessments, Volume III, London \& New York: Routledge, pp. 236-48. (1991b): "Descartes on Thought", in G. J. D. Moyal (ed.), René Descartes. Critical Assessments, Volume II, London \& New York: Routledge, pp. 288-95. (1991c): "A Brute to the Brutes? Descartes's Treatment of Animals", in G. J. D. Moyal (ed.), René Descartes. Critical Assessments, Volume IV, London \& New York: Routledge, pp. 323-31.

Curley, M. (1978): Descartes Against the Skeptics, Cambridge, Massachusetts: Harvard University Press.

Detlefsen, K. (ed.) (2013): Descartes' Meditations. A Critical Guide, Cambridge: Cambridge University Press.

FINE, G. (2000): "Descartes and Ancient Skepticism: Reheated Cabbage?", The Philosophical Review, no 109-2, pp. 195-234.

FreGE, G. (1997): “Thought”, in M. Beany (ed.), The Frege Reader, Oxford: Blackwell, 1997, pp. 325-45.

Glouberman, M. (1991): "Cartesian Substances as Modal Totalities", in G. J. D. Moyal (ed.), René Descartes. Critical Assessments, Volume III, London \& New York: Routledge, 1991, pp. 363-84.

HiLl, J. (2012): Descartes and the Doubting Mind, London \& New York: Continuum.

Kenny, A. (1968): Descartes. A Study of His Philosophy, New York: Random House.

Mijuskovic, B. (1991): "Descartes's Bridge to the External World: The Piece of Wax”, in G. J. D. Moyal (ed.), René Descartes. Critical Assessments, Volume II, London \& New York: Routledge, pp. 312-28.

Moyal, G. J. D. (ed.) (1991): René Descartes. Critical Assessments, Volumes I-IV, London \& New York: Routledge.

NAdler, S. N. (1989): Arnauld and the Cartesian Philosopby of Ideas, Manchester: Manchester University Press, 1989.

REID, T. (1941): Essays on the Intellectual Powers of Man, London: MacMillan, 1941. 
SOSA, E. (2007): A Virtue Epistemology. Apt Belief and Reflective Knowledge, Volume I, Oxford \& New York: Oxford University Press.

VendleR, Z. (1991): "Descartes on Sensation", in G. J. D. Moyal (ed.), René Descartes. Critical Assessments, Volume III, London \& New York: Routledge, pp. 249-59.

WagneR, S. I. (2014): Squaring the Circle in Descartes' Meditations. The Strong Validation of Reason, Cambridge: Cambridge University Press.

Wilson, C. (2005): "What Is The Importance of Descartes's Meditation Six?", Philosophica, $\mathrm{n}^{\circ}$ 76, pp. 67-90.

WitTGenstein, L. (2004): On Certainty, Oxford: Blackwell. 